\title{
A Rare Primary Headache Disorder: Headache Associated With Sexual Activity
}

\author{
Buse Cagla ARI ${ }^{1}$, Fusun Mayda Domac ${ }^{2}$, and Samiye Ulutas ${ }^{2}$ \\ ${ }^{1}$ Siirt State Hospital \\ ${ }^{2}$ Erenkoy Mental and Nervous Diseases Training and Research Hospital
}

May 6, 2020

\begin{abstract}
Background: Primary headache associated with sexual activity is a rare type of headache mostly seen in male gender and initiates at the 3rd decade. Even though the pathophysiology is still unknown, it is a benign type of headache and must be reminded on the differential diagnosis of the secondary headache. Materials\&Methods: Thirteen patients diagnosed as primary headache associated with sexual activity were evaluated by their clinical and demographic data. Results:Ten male and three female patients were evaluated. The mean age was $37.07 \pm 7.67$. Headache was usually localized at bilateral occipital area or diffuse, starting with a severe ache and sudden explosive intensity in association with preorgasm in 8 patients and orgasm in 5 patients with a mean VAS score of $7.8 \pm 1.2$. The mean duration was $21.53 \pm 15.32$ minutes. Five of the patients had a history of migraine, 3 had arteriel hypertension and two were diagnosed as primary thunderclap headache with sudden beginning and high intensity ache. Conclusion: Herein we presented our cases to highlight the importance of differential diagnosis. Patients may have difficulty of explaining the problem therefore their sexual activity could be limited.Apart from pharmacological prevention, counselling and facilitation plays important role in managing.
\end{abstract}

\section{Introduction}

Primary headache disorders associated with sexual activity (HAS) was formerly known as benign sexual/intercourse headache or orgasmic cephalalgia (1). It is frequently localized at occipital area, upper neck or spread as diffuse and triggered by sexual activity. It starts as dull at the beginning but as the sexual excitement rises, convertsto its most intense format the occurence of orgasm $(1,2)$. Even though it is benign, it can be a symptom of an underlying process on intracranial pathologies therefore neurovascular imaging should be performed for differential diagnosis (2-4).

The patients may find challenging to express the symptoms at onset due to the embarrassment. Once the diagnosis is completed it is treatable, the prognosis is good and the patients should be informed about the process. In an effort to increase awareness among specialists, we herein present the demographic and clinical data of our patients.

\section{Material and Methods}

Six hundred and fifty patients followed up at the Headache outpatient clinic of University of Health Sciences, Erenkoy Mental and Neurological Diseases Training and Research Hospital and Neurology clinic at Siirt State Hospital were determined. Thirteen patients who were diagnosed as primary headache diaorder associated with sexual activity according to headache classification of ICHD-3 criterias (2018) and were detailed by systematic and neurologic examination were included in. Patients without cranial computed tomography (CT), cranial magnetic resonance (MR) imaging, cranial MR angiography and cranial MR venography were not included to the study. Patients who have any other reasons for the origin of the headache got excluded. 
Patients were evaluated by gender, education, age at onset, localization, severity and duration of the headache as well as comorbidities. Headache severity was determined by using Visual Analogue Scale (VAS).

\section{Results}

Thirteen patients were diagnosed as primary headache disorders associated with sexual activity (2\%) according to ICDH-3 fulfilling criteria on table 1. Demographic and clinical features of the patients are described in table 2 and 3. Among these, 3 patients were female (76.9\%) and 10 were male $(23.1 \%)$. The mean age was $37.07 \pm 7.67$. Headache was usually localized at bilateral occipital area or diffuses, starting with a severe ache and sudden explosive intensity that is relevant with preorgasm in 8 patients and orgasm in 5 patients with a mean VAS score of $7.8 \pm 1.2$.

None of the patients had an aura. Photophobia, phonophobia, nausea or osmophobia were not accompanied. Three of the patients were experiencing the headache in each sexual intercourse. The mean duration was $21.53 \pm 15.32$ minutes. Five of the patients had a history of migraine, 3had arteriel hypertension and 2 were diagnosed as primary thunderclap headache with sudden onset and high intensity ache.

Patients were treated with indomethacin 30 minutes before sexual activity. Only 3 of the patients needed a prophylactic treatment with propranolol $80 \mathrm{mg}$ /day for 3 months. Patients were followed up for a year and none of the patients had recurrent headache.

\section{Discussion}

Primary headache associated with sexual activity is seen approximately in $0.9-1.6 \%$ of the population $(3,5)$. It may be developed at any sexually active age, seen in both genders but commonly in $3 \mathrm{rd}$ and $4^{\text {th }}$ decades, hypertensive or obese males in a ratio range between 1,2:1 - 3:1(1,2,6). In our patient group followed at headache outpatient clinic, $2 \%$ of the patients had primary headache with sexual activity. The mean age was $37.07 \pm 7.67$ and there was a male predominance relevant to the literature.

Even though the pathophysiology is not known exactly, one of the theories is to be a mechanism of trigeminovascular effect with the addition of muscular component and impaired cerebrovascular autoregulation $(1,7)$. Some authors suggested an excessive release of neurotransmitters or catecholamines $(8,9)$. Donnet et al have investigated the patients with craniocervical venography and detected venous stenosis in 12/19 of the patients suggesting this to promote the headache during the sexual activity (10).

Albeit it is classified as primary, at first onset it can be a symptom of subarachnoid hemorrhage, cerebral venous thrombosis, stroke, carotid artery dissection or reversible cerebral vasoconstriction syndrome therefore intracranial pathologies should be reminded on differential diagnosis so neurological (MR imaging), neurovascular imaging ( $M R$ angiography, MR venography ) and transcranial doppler ultrasonography must be performed $(11,12)$.

Initially it was used to be classified as three different types previously and $80 \%$ of the patients had been reported as orgasmic headache $(6,13)$. In our patient group only $38.5 \%$ of the patients had headache during orgasm. But on ICHD-3 these terms have been united as the pathophysiology has not been differentiated yet. The pain is characterized as dull and usually bilateral, must take at least two episodes, usually at occipital area, neck region or diffuse with the duration that lasts from minutes to hours as sexual activity increases and it becomes most powerful at orgasm. The headache appears individually from the type of sexual activity. In some researches it is believed that it can course up to one year $(1,2,7)$.

Extramarital sexual affairs may be a risk factor for HAS. Stress or fatigue may precipitate recurrent headache (14). In the literature 2 patients were reported with vertigo as an aura without headache during orgasm (11). The autonomic or vegetative symptoms do not usually accompany headache but a few patients may have nausea, phonophobia, photofobia or dizziness $(6,10)$. None of our patients had either aura or accompanying symptoms.

In preceding researches, it was suggested that there was a possible link between other primary headache disorders as migraine (19-30\%), tension type headache (27\%), cluster headache (2\%) and exertional headache 
(29-40\%) with HAS $(1,3,6,10,15-17)$. As both HAS and a primary exertional headache present a sudden initiation during an activity, it was suggested that in some of the patients with primary headache with sexual activity might be an analogue of exertion associated with orgasm (15). Primary sexual headache disorder was suggested to share the similar vascular hyperreactivity with migraine (18). Both migraine and HAS may have a genetic basis and both respond to prophylactic beta blockage therapy and acute treatment with naratiptan $(19,20)$. Both of the headache may present with vegetative symptoms and HAS may also be unilateral (20). Five of our patients had a preceding migraine history as suggested.

As concerns the treatment, prevention with indomethacin 30 minutes before sexual activity is sufficient in many cases but for the patients that suffer for a long-term period, the prophylaxis

could be made with indomethacin with the dosage between $25-50 \mathrm{mg} /$ day or propranolol $40-200 \mathrm{mg} /$ day for 3 to 6 months $(1,3,20)$.Ergotamine $1-2 \mathrm{mg} /$ day, diltiazem $180 \mathrm{mg} /$ day, topiramate $50 \mathrm{mg} /$ day and greater occipital nerve blockage are alternative options for the patients that can not tolerate drugs $(7,21-23)$. We have successfully treated 10 of patients with indomethacin before sexual activity and 3 patients were treated with propranolol prophylaxis.

In conclusion, even though primary headache associated with sexual activity is an infrequent syndrome, the awareness should be raised upon specialists and be reminded on differential diagnosis. Once the diagnosis is certain, it is important to provide the appropriate treatment, reassure the patient about its benign nature and self-limiting progress.

\section{Author Contributions}

BCA conceived, designed and analysed the data. FMD did editing.All authors discussed the results and reviewed the final manuscript. FMD did final approval.

\section{Conflicts of Interest}

None of the authors have either conflicts of interest or received any specific funding for this work.

\section{References}

1. Ks A, Dhikav V. Primary headache associated with sexual activity. Singapore Med J. 2009;50(5).

2. Headache Classification Committee of the International Headache Society (IHS) The International Classification of Headache Disorders, 3rd edition. Cephalalgia. 2018 Jan;38(1):1-211.

3. Utku U. Primary Headache Associated with Sexual Activity: Case Report. Med Princ Pract. 2013;22(6):588-9.

4. Goldstein J. Sexual aspects of headache: How sexual function relates to headaches and their causes and treatment. Postgraduate Medicine. 2001 Jan;109(1):81-92.

5. Biehl K, Evers S, Frese A. Comorbidity of migraine and headache associated with sexual activity. Cephalalgia. 2007 Nov;27(11):1271-3.

6. Frese A, Eikermann A, Frese K, Schwaag S, Husstedt I-W, Evers S. Headache associated with sexual activity: Demography, clinical features, and comorbidity. Neurology. 2003 Sep 23;61(6):796-800.

7. Ozcan T. Primary headache associated with sexual activity: A case report. Agri [Internet]. 2016 [cited $2020 \mathrm{Feb} 8$; ; Available from: http://www.agridergisi.com/jvi.aspx?pdir=agri\&plng=eng\&un=AGRI24654

8. Martin EA. Headache during sexual intercourse (coital cephalalgia). Ir J Med Sci 1974; 143:342-5. 5

9. Paulson GW, Klawans HL. Benign orgasmic cephalgia. Headache 1974; 13:181-7

10. Donnet A, Valade D, Houdart E, Lanteri-Minet M, Raffaelli C, Demarquay G, et al. Primary cough headache, primary exertional headache, and primary headache associated with sexual activity: a clinical and radiological study. Neuroradiology. 2013 Feb;55(3):297-305. doi: 10.1007/s00234-012-1110-0

11. Angus-Leppan H, Caulfeld A. Orgasmic migraine aura: report of two cases. Cephalalgia 2019 39(1):153156

12. González-Quintanilla V, Pascual J. Other Primary Headaches: An Update. Neurologic Clinics 2019;37(4), 871-891. 
13. Bahra A. Other primary headaches-thunderclap-, cough-, exertional-, and sexual headache. J Neurol. 2020 Mar 4. doi: 10.1007/s00415-020-09728-0

14. Silbert PL, Edis RH, Stewart-Wynne EG,Gubbay SS. Benign vascular sexual headache and exertional headache: interrelationships and long term prognosis. Journal of Neurology, Neurosurgery \& Psychiatry. 1991;54(5),417-421. doi:10.1136/jnnp.54.5.417

15. Lance JW. Headaches related to sexual activity. J Neuol Neurosurg Psychiatry 1976;39:1226-1230

16. Østergaard JR, Kraft M. Benign coital headache. Cephalalgia 1992;12: 353-355.

17. Pascual J, Iglesias F, Oterino A, Vazquez-Barquero A, Berciano J. Cough, exertional, and sexual headaches: An analysis of 72 benign and symptomatic cases. Neurology. 1996 Jun 1;46(6):1520-4.

18. Drummond PD, Lance JW. Neurovascular disturbances in headache patients. Clin Exp Neurol 1984;20:93-99.

19. Evans RW, Pascual J. Orgasmic headaches: clinical features, diagnosis, and management. Headache 2000; 40:491-4.

20. Porter M, Jankovic J. Benign coital cephalalgia. Arch Neurol 1981; 38:710-2.

21. Yeh Y-C, Fuh J-L, Chen S-P, Wang S-J. Clinical features, imaging findings and outcomes of headache associated with sexual activity. Cephalalgia. 2010 Nov;30(11):1329-35.

22. Bandini F, Arena E, Mauro G. Pre-orgasmic sexual headache responsive to topiramate: A case report. Cephalalgia. 2012 Jul;32(10):797-8.

23. Selekler M, Kutlu A, Dundar G. Orgasmic Headache Responsive to Greater Occipital Nerve Blockade. Headache: The Journal of Head and Face Pain. 2009 Jan;49(1):130-1.

Table 1. Clinical evaluation of the patients

Table 2. Demographic features of the patients

\begin{tabular}{|c|c|c|c|c|c|c|c|}
\hline Patients & Patients & Patients & Age at onset & Gender & VAS & $\begin{array}{l}\text { Duration of } \\
\text { severe pain } \\
\text { (min) }\end{array}$ & $\begin{array}{l}\text { Duration of } \\
\text { mild pain } \\
\text { (min) }\end{array}$ \\
\hline 1 & 1 & 1 & 51 & $*_{\mathrm{m}}$ & 8 & 20 & 30 \\
\hline 2 & 2 & 2 & 44 & $* *_{\mathrm{f}}$ & 6 & 10 & 60 \\
\hline 3 & 3 & 3 & 46 & $\mathrm{~m}$ & 9 & 15 & 10 \\
\hline 4 & 4 & 4 & 39 & $\mathrm{~m}$ & 10 & 10 &, 00 \\
\hline 5 & 5 & 5 & 41 & $\mathrm{~m}$ & 8 & 30 & 10 \\
\hline 6 & 6 & 6 & 28 & $\mathrm{~m}$ & 7 & 45 & 30 \\
\hline 7 & 7 & 7 & 41 & $\mathrm{~m}$ & 5 & 60 & 120 \\
\hline 8 & 8 & 8 & 36 & $\mathrm{f}$ & 8 & 20 & 60 \\
\hline 9 & 9 & 9 & 24 & $\mathrm{~m}$ & 10 & 5 &, 00 \\
\hline 10 & 10 & 10 & 32 & $\mathrm{f}$ & 6 & 15 &, 00 \\
\hline 11 & 11 & 11 & 36 & $\mathrm{~m}$ & 10 & 15 & 60 \\
\hline 12 & 12 & 12 & 35 & $\mathrm{~m}$ & 9 & 15 & 45 \\
\hline 13 & 13 & 13 & 29 & $\mathrm{~m}$ & 6 & 20 & 30 \\
\hline \multirow[t]{3}{*}{ Total } & $\mathrm{n}$ & $\mathrm{n}$ & 13 & 13 & 13 & 13 & 13 \\
\hline & Mean & Mean & 37.07 & 1.23 & 7.84 & 21.53 & 35 \\
\hline & Std. & Std. & 7.67 & 0.43 & 1.72 & 15.32 & 34.39 \\
\hline
\end{tabular}

*male, ${ }^{* *}$ female, min: minutes, $n$ : number

Table 3. Clinical features of the patients 


\begin{tabular}{|c|c|c|c|c|c|c|c|c|}
\hline Patients & Preorgasmic & Orgasmic & $P T P / P N P$ & $O P$ & $\begin{array}{l}\text { Happens } \\
\text { at all } \\
\text { sexual } \\
\text { activ- } \\
\text { ity? }\end{array}$ & Localization & Comorbidity & Treatm \\
\hline 1 & - & + & - & - & - & $\begin{array}{l}\text { occipital/ } \\
\text { diffuse }\end{array}$ & $a$ & indome \\
\hline 2 & + & - & - & - & - & unilateral & $a$ & indome \\
\hline 3 & + & - & - & - & - & unilateral & $b, c$ & indome \\
\hline 4 & + & - & - & - & + & $\begin{array}{l}\text { occipital/ } \\
\text { diffuse }\end{array}$ & - & indome \\
\hline 5 & - & + & - & - & - & $\begin{array}{l}\text { occipital/ } \\
\text { diffuse }\end{array}$ & $b$ & proprar \\
\hline 6 & + & - & - & - & + & unilateral & $a, c$ & proprar \\
\hline 7 & + & - & - & - & - & $\begin{array}{l}\text { occipital/ } \\
\text { diffuse }\end{array}$ & $b$ & proprar \\
\hline 8 & + & - & - & - & - & $\begin{array}{l}\text { occipital/ } \\
\text { diffuse }\end{array}$ & $a$ & indome \\
\hline 9 & + & - & - & - & - & unilateral & - & indome \\
\hline 10 & + & - & - & - & - & unilateral & $a$ & indome \\
\hline 11 & - & + & - & - & - & $\begin{array}{l}\text { occipital/ } \\
\text { diffuse }\end{array}$ & - & indome \\
\hline 12 & - & + & - & - & - & $\begin{array}{l}\text { occipital/ } \\
\text { diffuse }\end{array}$ & - & indome \\
\hline 13 & - & + & - & - & + & $\begin{array}{l}\text { occipital/ } \\
\text { diffuse }\end{array}$ & - & indome \\
\hline
\end{tabular}

a:migraine, b: arterial hypertention, c: primary thunderclap headache, PTP:photophobia, PNP: phonophobia, OP:osmophobia

\section{Hosted file}

table 1.docx available at https://authorea.com/users/318164/articles/448093-a-rare-primaryheadache-disorder-headache-associated-with-sexual-activity

\section{Hosted file}

Table 2.docx available at https://authorea.com/users/318164/articles/448093-a-rare-primaryheadache-disorder-headache-associated-with-sexual-activity

\section{Hosted file}

Table 3.docx available at https://authorea.com/users/318164/articles/448093-a-rare-primaryheadache-disorder-headache-associated-with-sexual-activity 